\title{
Study of the surface properties of $\mathrm{ZnO}$ nanocolumns used for thin-film solar cells
}

\author{
Neda Neykova ${ }^{* 1}$, Jiri Stuchlik ${ }^{1}$, Karel Hruska ${ }^{1}$, Ales Poruba ${ }^{1}$, Zdenek Remes ${ }^{1}$ \\ and Ognen Pop-Georgievski ${ }^{2}$
}

\author{
Full Research Paper \\ Address: \\ ${ }^{1}$ Institute of Physics AS CR v.v.i., Cukrovarnicka 10, 16253 Prague, \\ Czech Republic and ${ }^{2}$ Institute of Macromolecular Chemistry AS CR \\ v.v.i., Heyrovsky sq. 2, 16206 Prague, Czech Republic \\ Email: \\ Neda Neykova* - neykova@fzu.cz \\ * Corresponding author \\ Keywords: \\ 3-dimensional solar cells; hydrothermal growth; optical spectroscopy; \\ photothermal deflection spectroscopy; plasma treatment; X-ray \\ photoelectron spectroscopy; $\mathrm{ZnO}$ nanocolumns
}

Beilstein J. Nanotechnol. 2017, 8, 446-451. doi:10.3762/bjnano.8.48

Received: 12 September 2016

Accepted: 26 January 2017

Published: 16 February 2017

This article is part of the Thematic Series "Self-assembly of nanostructures and nanomaterials II".

Guest Editor: I. Berbezier

(C) 2017 Neykova et al.; licensee Beilstein-Institut. License and terms: see end of document.

\begin{abstract}
Densely packed $\mathrm{ZnO}$ nanocolumns (NCs), perpendicularly oriented to the fused-silica substrates were directly grown under hydrothermal conditions at $90{ }^{\circ} \mathrm{C}$, with a growth rate of around $0.2 \mu \mathrm{m} / \mathrm{h}$. The morphology of the nanostructures was visualized and analyzed by scanning electron microscopy (SEM). The surface properties of ZnO NCs and the binding state of present elements were investigated before and after different plasma treatments, typically used in plasma-enhanced CVD solar cell deposition processes, by X-ray photoelectron spectroscopy (XPS). Photothermal deflection spectroscopy (PDS) was used to investigate the optical and photoelectrical characteristics of the $\mathrm{ZnO} \mathrm{NCs,} \mathrm{and} \mathrm{the} \mathrm{changes} \mathrm{induced} \mathrm{to} \mathrm{the} \mathrm{absorptance} \mathrm{by} \mathrm{the} \mathrm{plasma} \mathrm{treatments.} \mathrm{A} \mathrm{strong}$ impact of hydrogen plasma treatment on the free-carrier and defect absorption of ZnO NCs has been directly detected in the PDS spectra. Although oxygen plasma treatment was proven to be more efficient in the surface activation of the ZnO NC, the PDS analysis showed that the plasma treatment left the optical and photoelectrical features of the ZnO NCs intact. Thus, it was proven that the selected oxygen plasma treatment can be of great benefit for the development of thin film solar cells based on ZnO NCs.
\end{abstract}

\section{Introduction}

The widely accepted design of thin-film silicon (TF-Si) solar cells, used for mass production, is composed of a transparent conductive oxide with roughness at the nanoscale on the front (TCO), e.g., tin oxide $\left(\mathrm{SnO}_{2}\right)$ or zinc oxide $(\mathrm{ZnO})$, followed by $\mathrm{p}-\mathrm{i}-\mathrm{n}$ Si layers (amorphous and/or nanocrystalline) in the cell and a back reflector $[1,2]$. In such a layer arrangement, the light scattering and the consequent light trapping, caused by the interfaces with nano-scale roughness (front TCO-active layer and active layer-back reflector), increase the optical path inside in the thin silicon layer. These effects are observed in the weakly absorbing spectral region of silicon above approximately $650 \mathrm{~nm}$, leading to efficiencies well above $13 \%$ at the 
cell level and above $12 \%$ at the module level $[3,4]$. However, the photo-generated current, determined by light absorption, is limited by the drift of generated electrons and holes across the absorber layer. Thus, the highest performances are expected for solar cells having a sufficiently large "optical thickness" and a sufficiently short distance between the electrodes, the "electrical thickness". In common planar TF-Si solar cells, it is impossible to simultaneously fulfil these two conditions. Recently developed solar cells based on a three dimensional (3-D) design, in which periodically ordered zinc oxide nanocolumns ( $\mathrm{ZnO} \mathrm{NCs})$ are used as a front electrode, have been of great interest, because they would exceed in the ultimate light trapping and provide excellent charge separation [5-7]. Due to the vertical geometry of these textures, the optical thickness is dictated by the height of the NCs, such that most of the light traversing the cell sees an absorber-layer thickness approximately equal to the NC height. In contrast, as the front and back TCO contacts are interpenetrating, the inter-electrode distance, given by the thickness of the Si layers on the walls of the NCs, is generally substantially thinner than that applied for state-ofthe-art a-Si:H solar cells; the lateral carrier transport provided by this type of texture should thus ensure an optimal current collection. Therefore, it is envisaged that in comparison to thinfilm planar cells with nano-scale roughness, the 3-D solar cells might lead to higher efficiency providing important assets such as minimal material consumption [8-10]. The proposed 3-D concept is not limited to thin-film silicon solar cells, but could be advantageously used for all other thin-film solar cells.

So far, a wide diversity of methods have been used for the preparation of $\mathrm{ZnO}$ nanocolumns such as metal organic chemical vapor deposition (MOCVD) [11], electrochemical deposition [12], sputtering [13], reactive ion etching [5] and the hydrothermal method $[6,14,15]$. The last mentioned is an attractive and preferable method for growing one-dimensional structures of $\mathrm{ZnO}$, as it is simple, does not require expensive equipment, is safe and environmentally friendly since water is used as a solvent, and it is easy to scale-up for further mass production.

Solar cell deposition is a multistep process during which different plasma processes are being used. Oxygen plasma is applied for both, activation of the surface and stripping of the polymer mask used for fabrication of periodically ordered $\mathrm{ZnO}$ NCs, while hydrogen plasma is usually used immediately before the deposition of the active solar-cell layer for directly increasing the electrical conductivity. The employed plasma treatments could significantly influence the concentration of defects and free carriers, reflected in the defect and free-carrier adsorption, and consequently impact the efficiency of the solar cell. Therefore, the investigation of the effects of the different plasma treatments on the $\mathrm{ZnO}$ nanocolumns is of crucial importance.
Herein, a low-temperature hydrothermal method is used to synthesize densely packed NCs on fused silica substrates covered with a $\mathrm{ZnO}$ seed layer, which were prepared before by $D C$ reactive magnetron sputtering. The optical absorption of the pristine $\mathrm{ZnO}$ layers as well as that of the substrates bearing the dense $\mathrm{ZnO}$ NCs was investigated by photothermal deflection spectroscopy (PDS) $[16,17]$. Furthermore, we investigated the changes in the PDS spectrum of the dense NCs induced by hydrogen and oxygen plasma treatment under conditions typical for plasma processing of thin-film silicon solar cells. XPS was used to determine the changes in surface composition as a result of the different plasma treatments.

\section{Results and Discussion}

Figure 1 reports SEM images of densely packed $\mathrm{ZnO}$ nanocolumns grown at $90{ }^{\circ} \mathrm{C}$ for $180 \mathrm{~min}$. As it can be seen from the SEM cross-sectional view, the $\mathrm{ZnO}$ nanocolumns are not interconnected and are well spaced with gaps of several nanometers. Notably, it is evident that each column has well defined boundaries (Figure 1a). The position of the individual nanocolumns is random with diameters varying from around 30 to $180 \mathrm{~nm}$, as revealed by the top-view SEM image (Figure 1b).

An average nanocolumn length of $650 \mathrm{~nm}$ was measured from the cross section, as shown in the SEM image of Figure 1a. The thickness of the seed layer is about $150 \mathrm{~nm}$. It should be noted, that after the hydrogen or oxygen surface plasma treatments the morphology of the nanocolumns does not change (see Figure S1 and Figure S2, Supporting Information File 1 for details).

The chemical bonding structure of the $\mathrm{ZnO}$ films prepared by hydrothermal growth from a seed layer on fused silica carriers was examined by XPS. Figure 2 reports typical XPS high-resolution $\mathrm{Zn} 2 \mathrm{p}$ and $\mathrm{O} 1 \mathrm{~s}$ spectra of the $\mathrm{ZnO}$ nanocolumns before and after $25 \mathrm{~min}$ of treatment in $\mathrm{H}$ - and O-plasma. The pristine $\mathrm{ZnO}$ NCs are characterized by a characteristic spin-split doublet with a $\mathrm{Zn} 2 \mathrm{p}_{3 / 2}$ peak centered at $1021.6 \mathrm{eV}$ and a $\mathrm{Zn} 2 \mathrm{p}_{1 / 2}$ peak (at $1044.7 \mathrm{eV}$ ) showing $23.1 \mathrm{eV}$ separation from the main contribution. The $\mathrm{O} 1 \mathrm{~s}$ spectrum of the as-prepared nanocolumns could be deconvoluted with three contributions arising from lattice oxygen $(\mathrm{Zn}-\underline{\mathrm{O}}-\mathrm{Zn})$, non-lattice oxygen $(\mathrm{Zn}-\underline{\mathrm{O}}-\mathrm{H}$, $\mathrm{Zn}-\underline{\mathrm{O}}^{-}$) and $\underline{\mathrm{O}}=\mathrm{C}$ moieties, and $\mathrm{C}-\underline{\mathrm{O}}-\mathrm{H}$ contributions centered at $530.4,531.7$ and $532.5 \mathrm{eV}$, respectively. The $\underline{\mathrm{O}}=\mathrm{C}$ and C- - $-\mathrm{H}$ contributions originate from organic contaminants adsorbed on the $\mathrm{ZnO}$ NCs surface during the transfer of the substrates to the XPS chamber.

The plasma treatments that are typically used in the solar cell fabrication processes, shift the position of the $\mathrm{Zn} 2 \mathrm{p}$ peaks by $0.3-0.4 \mathrm{eV}$ toward higher binding energies and significantly broaden their width, irrespectively of the exposure time. While 

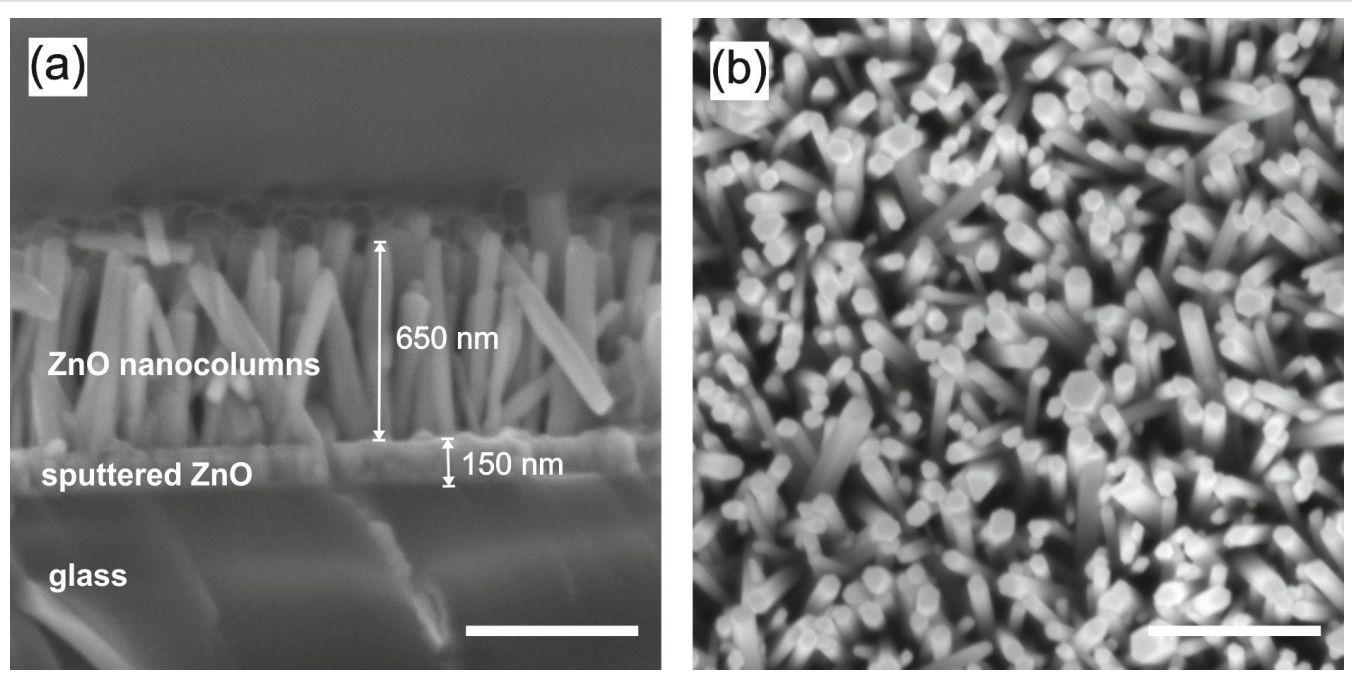

Figure 1: Cross-sectional (a) and top (b) view of densely packed ZnO NCs grown at $90^{\circ} \mathrm{C}$ for $180 \mathrm{~min}$ (scale bar: $500 \mathrm{~nm}$ ).
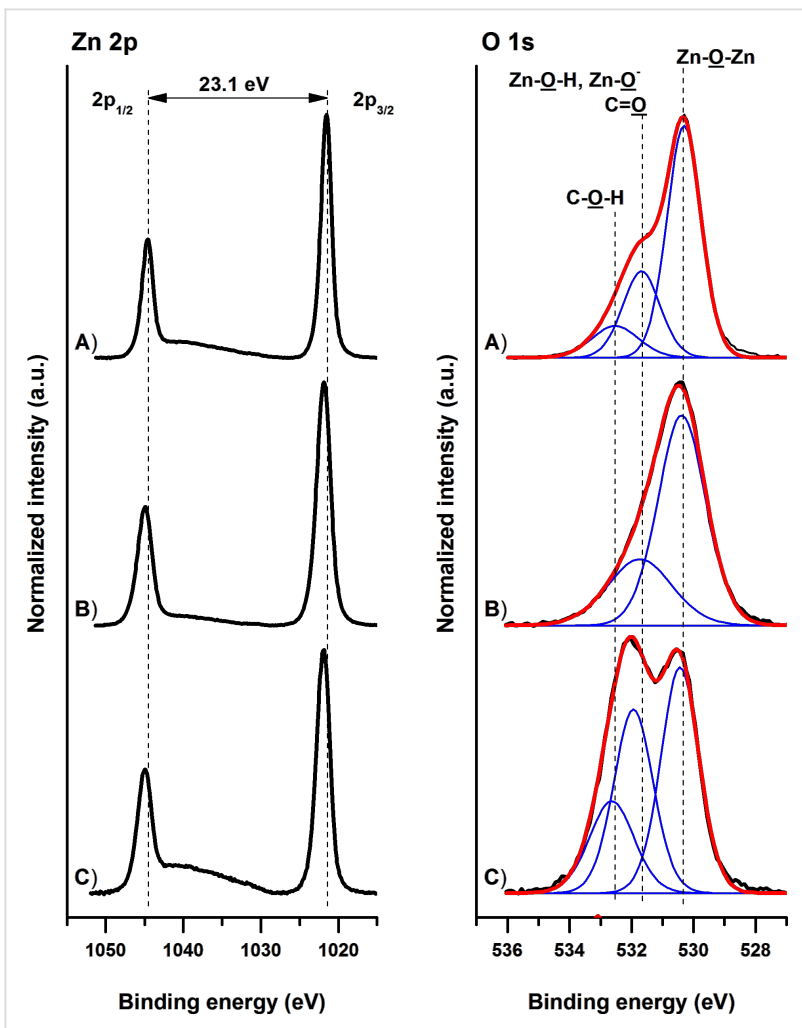

Figure 2: High-resolution core-level $\mathrm{Zn} 2 \mathrm{p}$ and $\mathrm{O}$ 1s XPS spectra of pristine (A) ZnO NCs and ZnO NCs after 25 min treatment in (B) $\mathrm{H}$ and (C) O-plasmas. Measured spectra are presented with black lines, while their corresponding fitted envelopes are presented in red. The individual contributions of different functional groups present in the $\mathrm{ZnO}$ nanocolumns are represented with blue lines.

the full width at half maximum (FWHM) of the pristine nanocolumns is about $1.8 \mathrm{eV}$, the FWHM of $\mathrm{H}$ - and O-plasma treated $\mathrm{ZnO}$ structures increased to 2.3 and $2.0 \mathrm{eV}$, respectively. The observed changes in the high-resolution $\mathrm{Zn} 2 \mathrm{p}$ spectra indi- cate the enhanced presence of surface defects, i.e., the existence of $\mathrm{Zn}$ atoms in different chemical surroundings. Concomitantly, the plasma treatment introduces changes in the highresolution $\mathrm{O} 1 \mathrm{~s}$ spectra and a strong increase of the contributions at about $531.7 \mathrm{eV}$, mainly due to the rise of the plasma induced $\mathrm{Zn}-\underline{\mathrm{O}-\mathrm{H}}$ and $\mathrm{Zn}-\underline{\mathrm{O}}^{-}$contributions [18]. Pristine nanocolumns are characterized by a ratio between the non-lattice

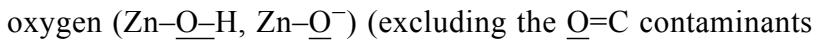
contributions) and the lattice $\mathrm{Zn}-\mathrm{O}-\mathrm{Zn}$ structures of 0.29. Upon the $\mathrm{H}$ - and O-plasma treatment this ratio rises to 0.43 and 0.60 , respectively. The concomitant observations in the high-resolution $\mathrm{Zn} 2 \mathrm{p}$ and $\mathrm{O} 1 \mathrm{~s}$ spectra were independent from the duration of the plasma treatment. The XPS data show an increase of defect density upon the plasma treatments in the surface area of the $\mathrm{ZnO}$ NCs, i.e., an increased presence of $\mathrm{Zn}-\mathrm{O}-\mathrm{H}$ and $\mathrm{Zn}-\underline{\mathrm{O}}^{-}$groups/species as a result of plasma seizure of the lattice $\mathrm{Zn}-\mathrm{O}-\mathrm{Zn}$ structures. The higher concentration of non-lattice oxygen ( $\mathrm{Zn}-\underline{\mathrm{O}-\mathrm{H}}$ and $\left.\mathrm{Zn}-\underline{\mathrm{O}}^{-}\right)$species in the case of O-plasma treatment evidences the more effective surface activation when this type of plasma is being used.

The changes induced to the synthesized $\mathrm{ZnO}$ NCs by the exposure to different plasma treatments was further probed by PDS. Figure 3 shows the optical absorptance spectra of as-grown $\mathrm{ZnO}$ nanocolumns and NCs treated in H-plasma for 1, 5, 10 and $25 \mathrm{~min}$. The measured PDS absorptance spectra reflect the absorption edge, Urbach tail, absorption on defects and freecarrier absorption (proportional to the concentration of free carriers).

All optical absorptance spectra show the optical absorption edge at a photon energy of $3.3 \mathrm{eV}$ and the free-carrier absorption in the red and the infrared part of the spectrum below photon ener- 


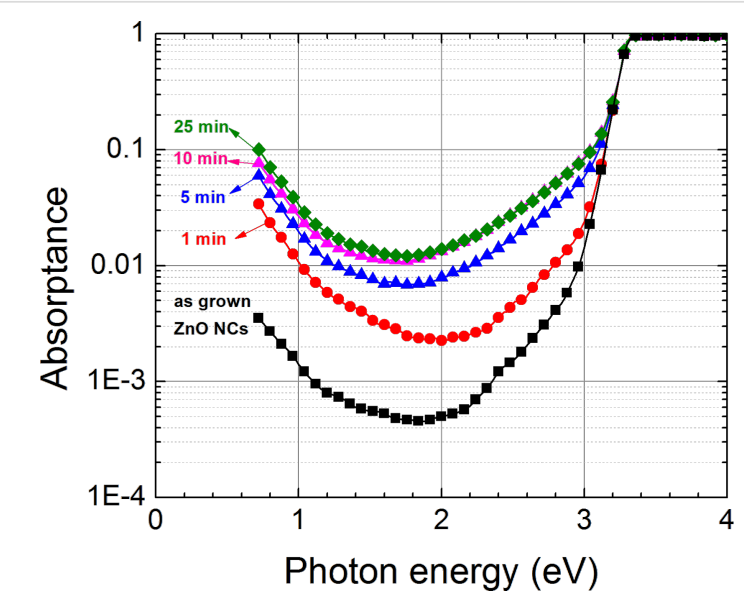

Figure 3: The optical absorptance spectra of as-grown $\mathrm{ZnO}$ nanocolumns and NCs treated in $\mathrm{H}$-plasma for 1, 5, 10 and 25 min.

gies of $2 \mathrm{eV}$. The infrared optical absorption increases with hydrogen plasma treatment indicating the increase of the freecarrier concentration as described in the Drude model. The increase of the free-carrier concentration is reasonably expected to increase the electrical conductivity of the $\mathrm{ZnO} \mathrm{NCs}$. Nevertheless, precise measurement of electrical conductivity is a difficult task and we plan to approach it by direct measurement on individual $\mathrm{ZnO}$ nanocolumns. The major changes appear within several minutes of exposure to hydrogen plasma and the effect saturates after about $10 \mathrm{~min}$. We suppose that hydrogen diffuses into $\mathrm{ZnO}$ creating shallow donors [19,20]. We note that the hydrogen doping does not shift the optical absorption edge [21], which means that the lattice as well as the occupancy of valence and conductive states does not change significantly (up to the degenerate conduction band) [22].

While the hydrogen plasma treatment induced significant changes in the optical absorptance spectra, notably, the PDS spectra show that there is no detectable change of the infrared optical absorptance (Figure 4). This observation strongly suggests that the O-plasma treatment does not have any detrimental effects on the free-carrier concentration in the $\mathrm{ZnO} \mathrm{NCs}$.

\section{Conclusion}

In this work, randomly arranged densely packed and preferentially perpendicularly oriented $\mathrm{ZnO}$ nanocolumn arrays were grown from seed layers on fused silica substrates. The surface composition of the $\mathrm{ZnO}$ NCs drastically changes upon the exposure to $\mathrm{H}$ - and O-plasma treatments. The plasma treatments increase the presence of non-lattice oxygen in the form of $\mathrm{Zn}-\mathrm{O}-\mathrm{H}$ and $\mathrm{Zn}-\mathrm{O}^{-}$contributions regardless of exposure time. The O-plasma treatment led to a more effective surface activation of the $\mathrm{ZnO}$ NCs as evidenced by the XPS analysis. The employed hydrogen-plasma treatment led to an increase of the

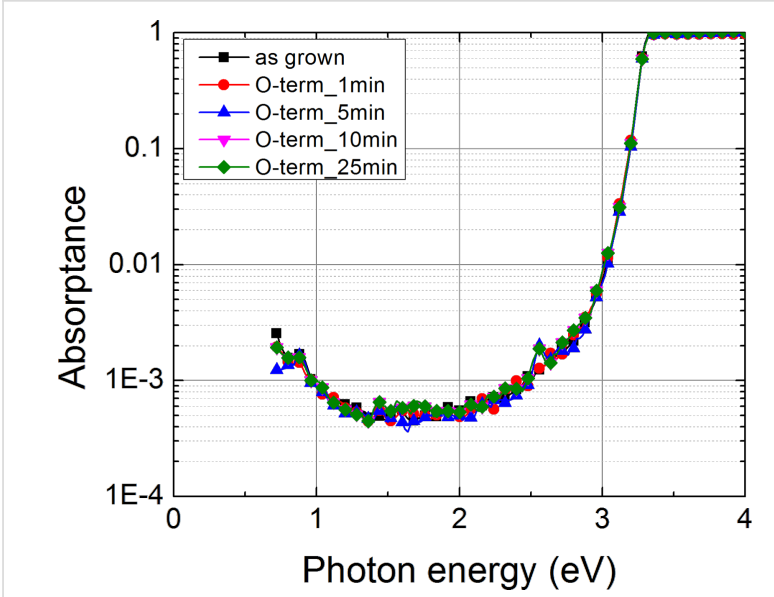

Figure 4: The optical absorptance spectra of as-grown $\mathrm{ZnO}$ nanocolumns and NCs treated in O-plasma for 1, 5, 10 and $25 \mathrm{~min}$.

free-carrier adsorption of up to two orders of magnitude, thus seriously affecting the optical and photoelectrical characteristics of the $\mathrm{ZnO}$ NCs. The oxygen-plasma treatment led to negligible changes in the PDS absorptance spectra. The concomitant increase in the presence of active surface species and only minor influence on the optical and photoelectrical features of the $\mathrm{ZnO} \mathrm{NCs}$ absorptance spectra, make the O-plasma a preferred treatment for the preparation of thin-film solar cells based on $\mathrm{ZnO}$ NCs. The reported $\mathrm{ZnO}$ nanocolumns layer with a proper spacing could be used as a 3-D scaffold not only for amorphous silicon solar cells, but also for other absorbers with a short lifetime such as $\mathrm{CuO}, \mathrm{CuO}_{2}, \mathrm{FeS}_{2}$, quantum dots or nanocrystalline Si.

\section{Experimental}

The growth of densely packed $\mathrm{ZnO}$ nanocolumns was performed on fused silica (Suprasil ${ }^{\circledR}$ ) substrates that were covered with an undoped thin seed layer of $\mathrm{ZnO}$ by DC reactive magnetron sputtering. The parameters of magnetron sputtering were as follows: processing temperature of $400{ }^{\circ} \mathrm{C}$ at a target voltage of $400 \mathrm{~V}$, ratio between gas species of $\mathrm{Ar} / \mathrm{O}=2 / 0.5$ for $10 \mathrm{~min}$.

The dimensions of all substrates were $10 \times 10 \mathrm{~mm}^{2}$. Before seed layer deposition, the substrates were cleaned in an ultrasonic bath with acetone for $10 \mathrm{~min}$, then rinsed with deionized water and dried under nitrogen flow.

The hydrothermal growth of $\mathrm{ZnO}$ nanocolumns was performed from an equimolar aqueous solution of $25 \mathrm{mmol}$ zinc nitrate hexahydrate $\left(\mathrm{Zn}\left(\mathrm{NO}_{3}\right)_{2} \cdot 6 \mathrm{H}_{2} \mathrm{O}\right)$ and hexamethylenetetramine $\left(\left(\mathrm{CH}_{2}\right)_{6} \mathrm{~N}_{4}\right)$ in an aqueous bath at $90{ }^{\circ} \mathrm{C}$ for $3 \mathrm{~h}[15,23]$. During the nanocolumns growth, the substrate was mounted upsidedown on a sample holder. After termination the sample was thoroughly washed in deionized water and dried in nitrogen 
flow. The surface morphology of the samples was characterized by SEM (MAIA3, TESCAN). The electron energies were $5 \mathrm{keV}$ or $10 \mathrm{keV}$. An in-lens detector was used to image the investigated surfaces.

\section{Plasma treatment}

Half of the as-prepared substrates with densely packed $\mathrm{ZnO}$ $\mathrm{NCs}$ were treated in oxygen plasma at $100 \mathrm{~W}, 0.5$ mbar for 1,5 , 10 and $25 \mathrm{~min}$ at room temperature (Femto, Diener electronic $\mathrm{GmbH})$.

The other half of the substrates underwent hydrogen plasma treatment, it was done in a capacitively coupled radio frequency plasma reactor KIII [24] at $20 \mathrm{~W}, 1$ mbar for 1, 5, 10 and $25 \mathrm{~min}$ at room temperature [25-27].

\section{X-ray photoelectron spectroscopy (XPS)}

XPS measurements were performed using a K-Alpha ${ }^{+}$XPS spectrometer (ThermoFisher Scientific, UK) operating at a base pressure of $1.0 \times 10^{-7} \mathrm{~Pa}$. The data acquisition and processing were performed using the Thermo Avantage software. All samples were analyzed using a microfocused, monochromated Al $\mathrm{K} \alpha \mathrm{X}$-ray radiation ( $400 \mu \mathrm{m}$ spot size) with a pass energy of $150 \mathrm{eV}$ for survey and $50 \mathrm{eV}$ for high-resolution core level spectra. The X-ray angle of incidence was $30^{\circ}$ and the emission angle was along the surface normal. The K-Alpha charge dual compensation system was employed during analysis, using electrons and low-energy argon ions to prevent any localized buildup of charge. The measured high-resolution spectra were fitted with Voigt profiles. The analyzer transmission function, Scofield sensitivity factors, and effective attenuation length for photoelectrons were applied for quantification. All spectra were referenced to the adventitious $\mathrm{C} 1 \mathrm{~s}$ peak at a binding energy (BE) of $285.0 \mathrm{eV}$. The BE scale was controlled on standards of poly(ethylene terephthalate) and metallic $\mathrm{Cu}, \mathrm{Ag}$, and $\mathrm{Au}$.

\section{Photothermal deflection spectroscopy (PDS)}

Measurements of optical absorption on bare sputtered $\mathrm{ZnO}$ substrates (not shown here) as well as on as-grown densely packed $\mathrm{ZnO} \mathrm{NCs}$ and further plasma-treated nanocolumns were carried out through photothermal deflection spectroscopy (PDS), a technique for measuring weak optical absorption in thin films $[14,28]$. Unlike optical transmittance spectroscopy, PDS detects directly the amount of the absorbed light by measuring the heat generated by the optical absorption with the optical absorptance sensitivity down to $0.01 \%$. PDS is based on measuring the deflection of the laser beam in the vicinity of the thin film immersed in a transparent liquid due to thermal changes of medium induced by heating of thin film by the absorption of the incident monochromatic light. A significant advantage of the PDS is the weak influence of the optical scattering, which is im- portant in the case of $\mathrm{ZnO}$ nanocolumns for which the transmittance spectra are significantly deteriorated by optical scattering.

\section{Supporting Information}

\section{Supporting Information File 1}

Additional SEM pictures.

[http://www.beilstein-journals.org/bjnano/content/

supplementary/2190-4286-8-48-S1.pdf]

\section{Acknowledgements}

This work was supported by the Czech Science Foundation under project 16-10429J. O.P.G. acknowledges the support from the European Regional Development Funds through the Operational Programme Prague - Competitiveness (Project number: CZ.2.16/3.1.00/21545).

\section{References}

1. Krishnakumar, V.; Han, J.; Klein, A.; Jaegermann, W. Thin Solid Films 2011, 519, 7138-7141. doi:10.1016/j.tsf.2010.12.118

2. Bosio, A.; Menossi, D.; Mazzamuto, S.; Romeo, N. Thin Solid Films 2011, 519, 7522-7525. doi:10.1016/j.tsf.2010.12.137

3. Shah, A.; Moulin, E.; Ballif, C. Sol. Energy Mater. Sol. Cells 2013, 119, 311-316. doi:10.1016/j.solmat.2013.09.001

4. Lin, J.; Cashmore, J.; Iwahashi, T.; Sakurai, J.; Losio, P.; Orhan, J. B.; Hoetzel, J.; Ristau, S.; Saito, Y.; Tsuji, A.; Roschek, T.; Meier, J.; Sinicco, I.; Zindel, A.; Hayashi, H.; Matsunaga, D. Blazing New Paths to High Efficiency Amorphous Silicon Based Solar Modules. Oral presentation at 40th IEEE Photovoltaics Specialist Conference, Denver, CO, USA, June 8-13, 2014. http://www.flip-programs.com/PVSC/PVSC-40-YB/

5. Vanecek, M.; Babchenko, O.; Purkrt, A.; Holovsky, J.; Neykova, N.; Poruba, A.; Remes, Z.; Meier, J.; Kroll, U. Appl. Phys. Lett. 2011, 98, 163503. doi:10.1063/1.3583377

6. Neykova, N.; Moulin, E.; Campa, A.; Hruska, K.; Poruba, A.; Stuckelberger, M.; Haug, F.-J.; Topic, M.; Ballif, C.; Vanecek, M. Phys. Status Solidi A 2015, 212, 1823-1829. doi:10.1002/pssa.201431869

7. Vanecek, M.; Neykova, N.; Hruska, K.; Poruba, A.; Remes, Z.; Holovsky, J.; Purkrt, A.; Babchenko, O.; Meier, J.; Kroll, U. Photovoltaic cell and methods for producing a photovoltaic cell. U.S. Patent US8772080B2, July 8, 2014.

8. Kim, J.; Battaglia, C.; Charrière, M.; Hong, A.; Jung, W.; Park, H.; Ballif, C.; Sadana, D. Adv. Mater. 2014, 26, 4082-4086. doi:10.1002/adma.201400186

9. Kuang, Y.; van der Werf, K. H. M.; Houweling, Z. S.; Schropp, R. E. I. Appl. Phys. Lett. 2011, 98, 113111. doi:10.1063/1.3567527

10. Ho, C.-I; Liang, W.-C.; Yeh, D.-J.; Su, V.-C.; Yang, P.-C.; Chen, S.-Y.; Yang, T.-T.; Lee, J.-H.; Kuan, C.-H.; Cheng, I-C.; Lee, S.-C. J. Appl. Phys. 2013, 113, 163106. doi:10.1063/1.4803045

11. Liu, X.-Y.; Shan, C.-X.; Wang, S.-P.; Zhao, H.-F.; Shen, D.-Z. Nanoscale 2013, 5, 7746. doi:10.1039/c3nr02263c

12. Elias, J.; Tena-Zaera, R.; Lévy-Clément, C. J. Electroanal. Chem. 2008, 621, 171-177. doi:10.1016/j.jelechem.2007.09.015 
13. Mamat, M. H.; Malek, M. F.; Hafizah, N. N.; Asiah, M. N.; Suriani, A. B.; Mohamed, A.; Nafarizal, N.; Ahmad, M. K.; Rusop, M. Ceram. Int. 2016, 42, 4107-4119. doi:10.1016/j.ceramint.2015.11.083

14. Neykova, N.; Brož, A.; Remeš, Z.; Hruška, K.; Kalbáčová, M.; Kromka, A.; Vaněček, M. Appl. Surf. Sci. 2012, 258, 3485-3489. doi:10.1016/j.apsusc.2011.11.101

15. Neykova, N.; Hruska, K.; Holovsky, J.; Remes, Z.; Vanecek, M. Thin Solid Films 2013, 543, 110-113. doi:10.1016/j.tsf.2013.02.110

16. Jackson, W. B.; Amer, N. M.; Boccara, A. C.; Fournier, D. Appl. Opt. 1981, 20, 1333-1344. doi:10.1364/AO.20.001333

17. Granqvist, C. G.; Hultåker, A. Thin Solid Films 2002, 411, 1-5. doi:10.1016/S0040-6090(02)00163-3

18. Chen, C.; Lu, Y.; He, H.; Xiao, M.; Wang, Z.; Chen, L.; Ye, Z. ACS Appl. Mater. Interfaces 2013, 5, 10274-10279. doi:10.1021/am403133u

19. Cox, S. F. J.; Davis, E. A.; Cottrell, S. P.; King, P. J. C.; Lord, J. S.; Gil, J. M.; Alberto, H. V.; Vilão, R. C.; Piroto Duarte, J.;

Ayres de Campos, N.; Weidinger, A.; Lichti, R. L.; Irvine, S. J. C. Phys. Rev. Lett. 2001, 86, 2601-2604. doi:10.1103/PhysRevLett.86.2601

20. Hofmann, D. M.; Hofstaetter, A.; Leiter, F.; Zhou, H.; Henecker, F.; Meyer, B. K.; Orlinskii, S. B.; Schmidt, J.; Baranov, P. G. Phys. Rev. Lett. 2002, 88, 045504. doi:10.1103/PhysRevLett.88.045504

21. Miloslavskii, V. K.; Pogrebniak, P. S. Phys. Status Solidi B 1972, 51, K99-K102. doi:10.1002/pssb.2220510252

22. Kim, Y. H.; Karazhanov, S. Zh.; Kim, W. M. Phys. Status Solidi B 2011, 248, 1702-1707. doi:10.1002/pssb.201046426

23. Greene, L. E.; Law, M.; Goldberger, J.; Kim, F.; Johnson, J. C.; Zhang, Y.; Saykally, R. J.; Yang, P. Angew. Chem., Int. Ed. 2003, 42, 3031-3034. doi:10.1002/anie.200351461

24. Stuchlik, J.; Stuchlikova, T. H.; Artemenko, A.; Remes, Z. JJAP Conf. Proc. 2015, 3, 011301. doi:10.7567/JJAPCP.3.011301

25. Neykova, N.; Kozak, H.; Ledinsky, M.; Kromka, A. Vacuum 2012, 86, 603-607. doi:10.1016/j.vacuum.2011.07.055

26. Pop-Georgievski, O.; Neykova, N.; Proks, V.; Houdkova, J.; Ukraintsev, E.; Zemek, J.; Kromka, A.; Rypaček, F. Thin Solid Films 2013, 543, 180-186. doi:10.1016/j.tsf.2012.11.128

27. Krátká, M.; Neykova, N.; Ukraintsev, E.; Kromka, A.; Rezek, B. Int. J. Electrochem. Sci. 2013, 8, 1598-1608.

28. Remes, Z.; Babchenko, O.; Varga, M.; Stuchlik, J.; Jirasek, V.; Prajzler, V.; Nekvindova, P.; Kromka, A. Thin Solid Films 2016, 618, 130-133. doi:10.1016/j.tsf.2016.04.026

\section{License and Terms}

This is an Open Access article under the terms of the Creative Commons Attribution License (http://creativecommons.org/licenses/by/4.0), which permits unrestricted use, distribution, and reproduction in any medium, provided the original work is properly cited.

The license is subject to the Beilstein Journal of Nanotechnology terms and conditions: (http://www.beilstein-journals.org/bjnano)

The definitive version of this article is the electronic one which can be found at:

doi:10.3762/bjnano.8.48 